Kevin B. Laupland Mathieu van der Jagt

\section{Manipulating vital signs in septic shock: which one(s) and how?}

Received: 21 August 2015

Accepted: 23 August 2015

Published online: 10 September 2015

(C) Springer-Verlag Berlin Heidelberg and ESICM 2015

K. B. Laupland

Department of Medicine, Royal Inland Hospital, Kamloops, BC, Canada

M. van der Jagt ( $\bullet$ )

Department of Intensive Care, Erasmus Medical Center, H-611, 's-Gravendijkwal 230, 3015 CE Rotterdam, The Netherlands e-mail: m.vanderjagt@erasmusmc.nl

Tel.: +31 107030478

The interplay between elevated body temperature and the outcome of critically ill patients is complex. While it is widely accepted-albeit with variable strength of the evidence-that control of fever in patients with neurological compromise is advantageous, in most other cohorts it is not clear [1,2]. On one hand, control of fever reduces metabolic demand and its treatment may be beneficial. On the other hand, fever is an adaptive response to infection and its treatment may be deleterious.

In their previous study, Schortgen and colleagues randomized patients with septic shock to a regimen of either permissive fever or external cooling to a normothermia goal [3]. They observed a significant positive effect not only on their primary outcome of reduced vasopressor use but also on overall mortality associated with temperature control (14-day mortality $19 \%$ with cooling vs. $34 \%$ in controls, $p=0.013$ ). In the present study, they conducted a further secondary analysis in order to investigate the confounding effects of heart rate on mortality. This question was raised in part related to an open label clinical trial that showed a significant reduction in mortality among septic shock patients randomized to heart rate control (<95/min) by means of an esmolol infusion as compared to controls [4]. In their present analysis, they observed that the effect of temperature control on mortality was not mediated by control of heart rate.

Based on these data, one may come to the conclusion that fever should be controlled in patients with septic shock. However, there are some key issues which must be taken into consideration.

While the results of the original study by Schortgen are compelling [3], treatment of fever in septic patients has been by no means conclusively demonstrated to be beneficial. Observational studies including hundreds of thousands of patients have documented highly variable results $[5,6]$. In addition, the overall body of clinical trials to date investigating anti-pyretic therapy in critically ill neurologically intact patients has not shown any overall benefit [7]. Finally, we have observed numerous examples of small studies demonstrating dramatic mortality reductions associated with a number of different interventions in septic shock that could not be replicated in subsequent larger definitive studies [8,9].

Another important consideration in evaluating the studies reported by Schortgen et al. is that the confounding effects of beta-blocker use on outcome, whether successful or not in heart rate control, is not clear. Similarly, the study by Morelli et al. did not report on specifics regarding temperature control [4]. While the current study by Schortgen et al. supports that the effect of temperature control on outcome is independent of heart rate, we are left wondering what would have been the effect of temperature had betablockade been applied systematically? To adequately address this question, the development of a factorial randomized control trial is required.

Further, in a more general sense, it is key to distinguish whether vital signs such as temperature and heart rates are elevated or decreased as a beneficial compensatory mechanism, implying that they should be left alone, or that vitals represent exhausted or counterproductive values which require manipulation by critical care specialists (Fig. 1) [10]. This is highly complex given that the transition of a vital sign from compensating (physiological) to decompensating (or pathological) may depend on 
Fig. 1 Vital signs or physiological variables are measurable physical parameters at the bedside. In critically ill patients with septic shock, each of these parameters may be elevated or decreased to compensate for demands posed on one or more organ systems to maintain the patient's physical integrity. Several levels of compensation (blue and red text bars) are shown. The compensation should generally be accepted when it is moderate (i.e., not directly manipulated) but extremes may require immediate intervention (see text)

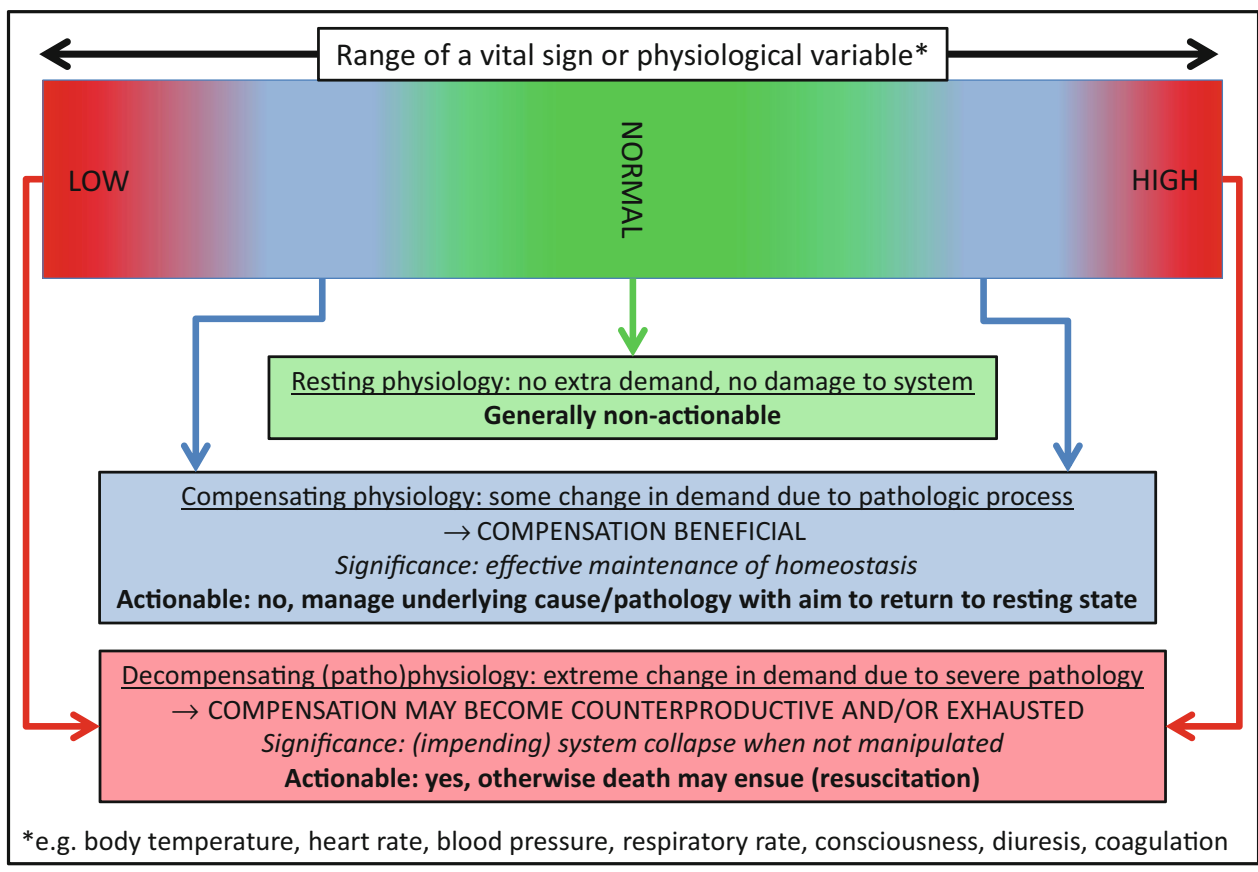

many simultaneously acting circumstances, such as the underlying disease, the cross-talk with other affected organs, and physiological reserve of the patient. Furthermore, these may vary both inter- and intraindividually over time. Examples of such transitions into decompensated vitals on which more consensus exists include malignant hyperthermia (i.e., cool the patient), stress cardiomyopathy (i.e., start inotropic drugs) but also hypotension in compensated heart failure in an outpatient situation versus hypotension in cardiac shock. With regard to the example of heart failure, it is obvious that the patient with a blood pressure of $80 / 50 \mathrm{mmHg}$ with compensated heart failure requires no intervention, whereas progression to decompensated heart failure and subsequent shock in another patient with the same blood pressure requires immediate treatment. So, theoretically, trials that include both the physiologically compensated and decompensated subjects for interventions that modify specific vital signs (e.g., blood pressure) may wrongfully practise "one size fits all", when in fact selection for such interventions based on specific patient characteristics- even with a remarkably similar underlying condition-is essential.

Support and manipulation of the vital signs (blood pressure, respiratory rate, heart rate, and temperature) is central to and arguably defines the practice of critical care medicine. It is therefore disappointing that the body of clinical trials literature directed at evaluating vital sign manipulations on outcome in patients with septic shock is so limited [11]. The lack of such studies may be due to the fact that it seems overly simplistic that manipulation of a single vital sign variable such as temperature or heart rate should have a profound effect on the mortality outcome of complex critically ill patients. While we thank Dr. Schortgen and colleagues for their important contribution furthering our information on this topic, we believe the question of management of fever and tachycardia in septic shock patients still remains an unanswered one of treating none, one, or both.

\section{Compliance with ethical standards}

Conflicts of interest Both authors report no conflict of interest.

\section{References}

1. Niven DJ, Laupland KB (2013) Pharmacotherapy of fever control among hospitalized adult patients. Expert Opin Pharmacother 14:735-745
2. Launey Y, Nesseler N, Malledant Y, Seguin P (2011) Clinical review: fever in septic ICU patients-friend or foe? Crit Care Med 15:222
3. Schortgen F, Clabault K, Katsahian S, Devaquet J, Mercat A, Deye N, Dellamonica J, Bouadma L, Cook F, Beji O, Brun-Buisson C, Lemaire F, Brochard L (2012) Fever control using external cooling in septic shock: a randomized controlled trial. Am J Resp Crit Care Med 185:1088-1095 
4. Morelli A, Ertmer C, Westphal M, Rehberg S, Kampmeier T, Ligges S, Orecchioni A, D'Egidio A, D'Ippoliti F, Raffone C, Venditti M, Guarracino F, Girardis M, Tritapepe L, Pietropaoli P, Mebazaa A, Singer M (2013) Effect of heart rate control with esmolol on hemodynamic and clinical outcomes in patients with septic shock: a randomized clinical trial. JAMA 310:1683-1691

5. Young PJ, Saxena M, Beasley R, Bellomo R, Bailey M, Pilcher D, Finfer S, Harrison D, Myburgh J, Rowan K (2012) Early peak temperature and mortality in critically ill patients with or without infection. Intensive Care Med 38:437-444

6. Laupland KB, Zahar JR, Adrie C, Schwebel C, Goldgran-Toledano D, Azoulay E, Garrouste-Orgeas M, Cohen Y, Jamali S, Souweine B, Darmon M, Timsit JF (2012) Determinants of temperature abnormalities and influence on outcome of critical illness. Crit Care Med 40:145-151
7. Niven DJ, Stelfox HT, Laupland KB (2013) Antipyretic therapy in febrile critically ill adults: a systematic review and meta-analysis. J Crit Care 28:303-310

8. Sprung CL, Annane D, Keh D, Moreno R, Singer M, Freivogel K, Weiss YG, Benbenishty J, Kalenka A, Forst H, Laterre PF, Reinhart K, Cuthbertson BH, Payen D, Briegel J, Group CS (2008) Hydrocortisone therapy for patients with septic shock. N Engl J Med 358:111-124

9. Ranieri VM, Thompson BT, Barie PS, Dhainaut JF, Douglas IS, Finfer S, Gardlund B, Marshall JC, Rhodes A, Artigas A, Payen D, Tenhunen J, AlKhalidi HR, Thompson V, Janes J, Macias WL, Vangerow B, Williams MD (2012) Drotrecogin alfa (activated) in adults with septic shock. N Engl J Med 366:2055-2064
10. Van der Jagt M, Miranda DR (2012) Beta-blockers in intensive care medicine: potential benefit in acute brain injury and acute respiratory distress syndrome. Recent Pat Cardiovasc Drug Discov 7:141-151

11. Asfar P, Meziani F, Hamel JF, Grelon F, Megarbane B, Anguel N, Mira JP, Dequin PF, Gergaud S, Weiss N, Legay F, Le Tulzo Y, Conrad M, Robert R, Gonzalez F, Guitton C, Tamion F, Tonnelier JM, Guezennec P, Van Der Linden T, Vieillard-Baron A, Mariotte E, Pradel G, Lesieur O, Ricard JD, Herve F, du Cheyron D, Guerin C, Mercat A, Teboul JL, Radermacher P (2014) High versus low blood-pressure target in patients with septic shock. N Engl J Med 370:1583-1593 